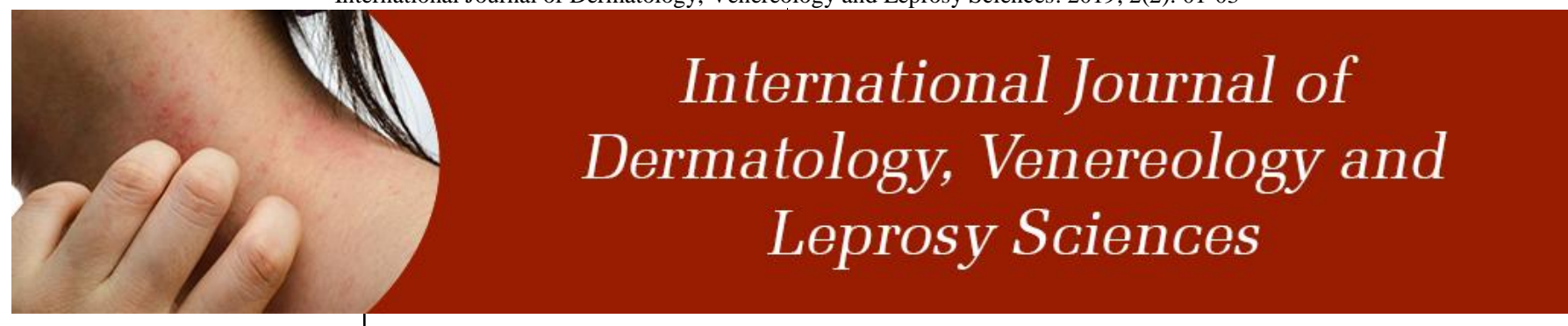

E-ISSN: 2664-942X

P-ISSN: 2664-9411

www.dermatologypaper.com

Derma 2019; 2(2): 01-03

Received: 02-05-2019

Accepted: 04-06-2019

Kyaw Wai

Department of Dermatology,

Myanmar Mercantile Marine

College, Yangon, Myanmar
Corresponding Author: Kyaw Wai

Department of Dermatology,

Myanmar Mercantile Marine

College, Yangon, Myanmar

\title{
Postmenopausal related dermatoses- A clinical study
}

\section{Kyaw Wai}

DOI: https://doi.org/10.33545/26649411.2019.v2.i2a.22
Abstract

Introduction: Skin disease here refers to disorders of exclusively the superficial layers of the skin. The present study assessed postmenopausal related dermatoses.

Materials \& Methods: The present study was conducted on 84 postmenopausal patients with dermatoses. Investigations including $\mathrm{KOH}$, smear, Wood's lamp examination, and biopsy were done. Dermatoses were recorded.

Results: 24 patients were housewives, 32 were labourer and 28 were farmer. The difference was significant $(P<0.05)$. Common dermatoses was lichen planus in 15, Psoriasis in 10, Eczema in 18 , vitiligo in 20, melasma in 7, bacterial infection in 5, Onychomycosis in 6 and Pemphigus vulgaris in 4 cases. The difference was significant $(P<0.05)$.

Conclusion: Authors found common dermatoses in post menopausal females was lichen planus, Psoriasis, Eczema, vitiligo, melasma, bacterial infection, Onychomycosis and Pemphigus vulgaris.

Keywords: Dermatoses, Eczema, Post menopausal

\section{Introduction}

Skin disease here refers to disorders of exclusively the superficial layers of the skin. Premature menopause can occur due to surgery, irradiation, viral infection, eg., mumps, various enzymatic, or hormonal defects and systemic disorders like Addison's disease, rheumatoid arthritis, diabetes mellitus, or myasthenia gravis ${ }^{[1]}$. Menopause is preceded by a period, which is called menopausal transition, peri-menopause, or climacteric a time of change and readjustment to new phase which menopause brings 'A Step up the ladder' ${ }^{\text {[2] }}$

There are many factors that influence menopausal age including heredity (age of mothers menopause), smoking, parity, socioeconomic factors, exposure to various toxins, and nutrition. Menopause syndrome due to estrogen deficiency can be classified as physical or psychological ${ }^{[3]}$. Physical symptoms include vasomotor symptoms such as hot flushes and night sweats, urogenital symptoms, palpitations, headaches, bone and joint pain, asthenia, tiredness, disturbed sleep or insomnia, breast tenderness, and skin aging. Psychological symptoms include depression, memory loss, irritability, poor concentration, tiredness, depressed mood, mood swings, loss of libido, anxiety, and loss of confidence ${ }^{[4]}$.

Menopause brings changes in collagen metabolism. Postmenopausal period is marked by low amounts of soluble collagen, slow turnover, and collagen synthesis resulting in decreased skin resilience and pliability. Skin loses its suppleness, with a feeling of intense tingling and formication owing to the effect on the neurovascular network in the skin collagen, which is largely influenced by sex hormones, especially estrogen, which declines after menopause ${ }^{[5]}$. The present study assessed postmenopausal related dermatoses.

\section{Materials \& Methods}

The present study was conducted in the department of Dermatology. It comprised of 84 postmenopausal patients with dermatoses. All patients were informed regarding the study and written consent was obtained. Ethical clearance was taken before starting the study.

General information such as name, age, etc. was noted. Investigations including $\mathrm{KOH}$, smear, Wood's lamp examination, and biopsy were done. Dermatoses were recorded. Results thus obtained were subjected to statistical analysis. $\mathrm{P}$ value less than 0.05 was considered significant. 


\section{Results}

Table I: Occupation of subjects

\begin{tabular}{|c|c|c|}
\hline Occupation & Number & P value \\
\hline Housewife & 24 & \multirow{2}{*}{0.01} \\
\cline { 1 - 2 } Labourer & 32 & \\
\hline Farmer & 28 & \\
\hline
\end{tabular}

Table I shows that 24 patients were housewives, 32 were labourer and 28 were farmer. The difference was significant $(P<0.05)$.

Table II: Dermatoses in patients

\begin{tabular}{|c|c|c|}
\hline Dermatoses & Number & P value \\
\hline Lichen planus & 15 & \\
\cline { 1 - 2 } Psoriasis & 10 & \\
\hline Eczema & 18 & \multirow{2}{*}{0.01} \\
\hline Vitiligo & 20 & \\
\hline Melasma & 7 & \\
\hline Bacterial infection & 5 & \\
\hline Onychomycosis & 6 & \\
\hline Pemphigus vulgaris & 4 & \\
\hline
\end{tabular}

Table II, graph I shows that common dermatoses was lichen planus in 15, Psoriasis in 10, Eczema in 18, vitiligo in 20, melasma in 7, bacterial infection in 5, Onychomycosis in 6 and Pemphigus vulgaris in 4 cases. The difference was significant $(P<0.05)$.

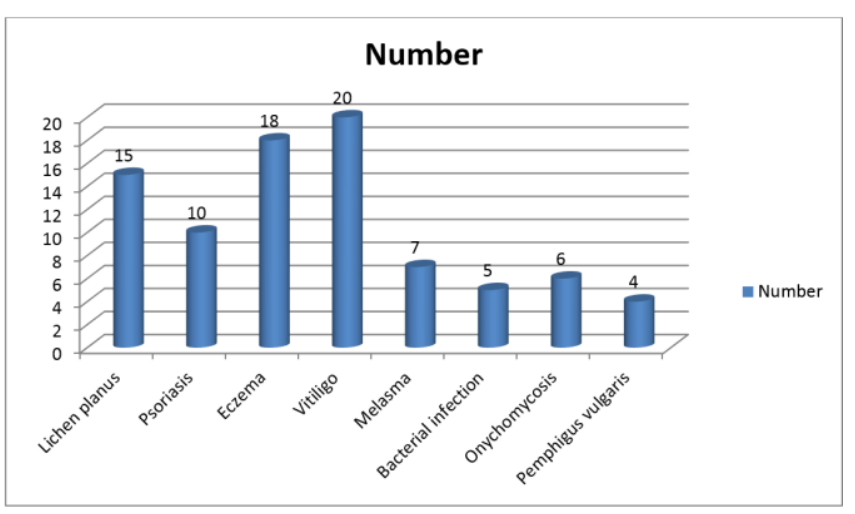

Graph I: Dermatoses in patients

\section{Discussion}

The life expectancy in India has been increasing, according to WHO health statistics 2011 in India, an average female life expectancy is 68 years and is projected to increase up to 73 years by 2021. With about 25 million women passing through the menopause each year and rising, menopause and its associated symptoms have become key areas of interest [6]. Menopause is defined as the permanent, irreversible cessation of menses (not having a menstrual period for 12 consecutive months) brought about by a decline in ovarian follicular activity. In most women, menopause occurs between the ages of 50-55 years, with an average age of 51.5 years, but some have their menopause before the age of 40 (premature menopause), whereas a few may menstruate until they are in their 60s. The estimated mean age of menopause is 46 years in India which is lower than Caucasians ${ }^{[7]}$.

A multitude of factors, including lifestyle and role, body image, interpersonal relationships, and sociocultural status, can influence a woman's attitude toward the menopause and impact on her perception of symptom severity. The abundance of estrogen receptors in both dermis and epidermis and to a lesser extent progesterone receptor shows that skin is significantly affected during menopause ${ }^{[8]}$.

Extrinsic cutaneous aging is a type of premature skin aging occurs by exposing the skin to harmful environmental factors such as poor nutrition, smoking, sun exposure, and large alcohol intake. Intrinsic skin aging is believed to occur as a result of telomere shortening. Telomeres also play a role in lowering oxidative damage in cells. Atrophy of dermis occurs with decreased collagen, fibroblasts, mast cells, and blood vessels. Skin wrinkles become translucent, dry, flaky, and fragile, making it more prone to trauma, bleeding, and infection [9]. The present study assessed postmenopausal related dermatoses.

In present study, 24 patients were housewives, 32 were labourer and 28 were farmer. We found that common dermatoses was lichen planus in 15, Psoriasis in 10, Eczema in 18 , vitiligo in 20 , melasma in 7 , bacterial infection in 5 , Onychomycosis in 6 and Pemphigus vulgaris in 4 cases.

Pariath et al. ${ }^{[10]}$ included 150 postmenopausal women. Most of the patients belonged to the age group of 61-70 years $(38.67 \%)$ with a mean age of 61.52 years. The age of menopause was most commonly achieved between 40 and 50 years $(57.33 \%)$. The genital dermatoses were found in 90 $(60 \%)$ subjects and included atrophic vaginitis (33.33\%), lichen sclerosus et atrophicus $(14,15.55 \%)$, lichen simplex chronicus (15.55\%) and tinea cruris (11.11\%) among others. The extragenital dermatoses were found in $96(64 \%)$ cases and common ones were dermatophytosis (16.33\%), lichen planus $(11,11.22 \%)$, psoriasis $(9.18 \%)$ and eczema $(8.16 \%)$.

\section{Conclusion}

Authors found common dermatoses in post menopausal females was lichen planus, Psoriasis, Eczema, vitiligo, melasma, bacterial infection, Onychomycosis and Pemphigus vulgaris.

\section{References}

1. Meeta, Digumarti L, Agarwal N, Vaze N, Shah R, Malik S. Clinical practice guidelines on menopause: An executive summary and recommendations. J Midlife Health. 2013; 4:77-106.

2. Kuhle BX. An evolutionary perspective on the origin and ontogeny of menopause. Maturitas. 2007; 57:32937.

3. Nair PA. Dermatosis associated with menopause. J Midlife Health. 2014; 5:168-75.

4. Aboobacker S, Saritha M, Karthikeyan K. A retrospective analysis of dermatoses in the perimenopausal population attending a tertiary care centre in South India. J Midlife Health. 2015; 6:115-21.

5. Ahuja M. Age of menopause and determinants of menopause age: A PAN India survey by IMS. J Midlife Health. 2016; 7:126-31.

6. Jahan U, Pradeep Y, Hussain N. Prevalence of atrophic vaginitis in post-menopausal women of Northern India and role of vaginal maturation value in its diagnosis. Int J Med Res Prof. 2017; 3:170-3.

7. Singh M. Early age of natural menopause in India, a biological marker for early preventive health programs. Climacteric. 2012; 15:581-6.

8. Kapur P, Sinha B, Pereira BM. Measuring climacteric symptoms and age at natural menopause in an Indian 
population using the Greene climacteric scale. Menopause. 2009; 16:378-84.

9. Singh A, Pradhan SK. Menopausal symptoms of postmenopausal women in a rural community of Delhi, India: A cross-sectional study. J Midlife Health. 2014; 5:62-7.

10. Pariath K, Nair PA. A cross-sectional study on the dermatoses in postmenopausal patients at a rural-based tertiary health care center. Indian J Dermatol. 2019; 64:360-5. 